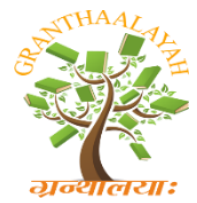

\author{
INTERNATIONAL JOURNAL OF RESEARCH - \\ GRANTHAALAYAH \\ A knowledge Repository
}

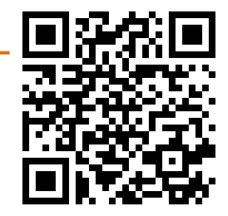

Science

\title{
SYNTHESIS OF SOME DIAZINE AND TRIAAZOLE DERIVATIVES FROM FURFURAL
}

\author{
Al-Ajely M.S ${ }^{1}$, Shaban I.M ${ }^{2}$ \\ ${ }^{1}$ Environmental Department, Environmental College, Mosul University, Mosul-Iraq \\ ${ }^{2}$ Agricultural Technical College, Northern Technical University, Mousel-Iraq
}

\begin{abstract}
The synthesis of heterocyclic compounds especially when their structure containing nitrogen ,oxygen and sulfur atoms are growing up due to their wide spread in nature, many mechanistic pathways to reach the target with nearly negligible loss of their dose and there are numerous me thods to derivatives their structures There for the development in hetero cyclic synthesis will provide new metabolic pathways when these compounds have succeeded to be used as drug ,Moreover it was known for long time that about $95 \%$ of cancer drugs are heterocyclic compounds .There are also many methods found in the literature for the synthesis of both triazoles and trdiazines from different routes In this investigation furfural was used as precursor for the synthesis of some new diazine and triazole derivatives (3-11). The synthesized compounds were characterized by IR , and 1HNMR and are discussed.
\end{abstract}

Keywords: Diazine; Triazine Derivatives; Synthesis; Furfural.

Cite This Article: Al-Ajely M.S, and Shaban I.M. (2019). "SYNTHESIS OF SOME DIAZINE AND TRIAAZOLE DERIVATIVES FROM FURFURAL." International Journal of Research Granthaalayah, 7(4), 83-89. https://doi.org/10.29121/granthaalayah.v7.i4.2019.877.

\section{Introduction}

Heterocyclic compound are important class of organic chemistry due to their wide spread in nature and there is versatile ways to synthesize them and also many site are available of functionalization for a given structure. Different metabolic pathways of heterocyclic compounds associated with living organism encouraged researchers to introduce different ways for synthesizing these types of compounds ,These researchers spent much efforts to design these types of compounds as drugs[14].Since drugs needs to reach the target at certain time to penetrate through body tissue without interference with other cells and maintain it's does through this pathway. Accordingly, heterocyclic compounds were found to be used for many biological, clinical and pharmaceutical applications [5-7]. Furfural for example 2-(2-furyl) [1,3] dioxane,5-nito(1,3-imidazolyl-2,5-dion)3 -yl furfurlidine was found to be used for treatment of urinary tract [8-10] also furfural derivatives were used for different biological applications[11,12] It was also known that many triazoles and diazines compounds were synthesized from different routes[ 13-16]. Some heterocyclic 
compound derived from furfural were prepared previously [17] and here we are going to complete this work by using furfural as precursor for other new heterocyclic compounds which might find an applications as drugs ,since Triazoles such as fluconazole, Isavuconazole, Hexaconazole, epoxiconazole, difenoconazole, tebuconazole etc.,) were commercially used as a fungicidal drugs[18]. In this investigation we use furfural molecule as a core compound for heterocyclic synthesis including diazoles, triazoles so that to increase their activity through introducing furfural moiety toward their synthesis in a way that will make them suitable for this type of studies which will be investigated in our next work. The synthesized compounds were studied by IR and one of them by ${ }^{1} \mathrm{HNMR}$ and used for elucidating their structures..

\section{Experimental}

Melting point were measured using electrothermal melting point apparatus type IR spectra were measured using Infra-red spectrophoto meter model Tensor 27 Bruker 1HNMR spectra were performed using Bruke $400 \mathrm{MHz}$. All chemical compound were supplied by Aldrich, Fluka,BDH chemical companies . Compound 1 was prepared using the published procedure [19], compounds

2 was prepared following the else were published procedure [20 ], Their mp. and IR , ${ }^{1} \mathrm{HNMR}$ spectra were the same of the published one.

\subsection{Synthesis of 5-Bromo-6-phenyl-2-benzoyl pyridine-3(1H) one (3)}

This compound was prepared following similar procedure [21], A mixture of 0.02 mal ,5.02g of compound (2) and (0.02 mal ,3.739g) of benzoyl chloride in $100 \mathrm{ml}$ of dry benzene was refluxed with continuous stirring for 24 hour under dry condition. The solvent was evaporated under reduced pressure. The residue was dried and crystallized from ethanol to afford brown powder mp. 194-196 ${ }^{\circ} \mathrm{C}, 65 \%$ yield.IR : $1697 \mathrm{~cm}^{-1}, 1658 \mathrm{~cm}^{-1}, 1496-1621 \mathrm{~cm}^{-1}$ and $870 \mathrm{~cm}^{-1}$.

\subsection{Synthesis of 5-Bromo-2-(chloro methyl)-6-phenyl pyradazin-3-(2H)-one (4)}

A mixture of (0.01 mol. ,2.5 g.) of compound (3) and paraform aldehyde $1.5 \mathrm{~g}$. And $3 \mathrm{ml}$ of thionyl chloride in $50 \mathrm{ml}$ of dry benzene was refluxed for one hour, cooled and filtered, the filterate was then evaporated under reduced pressure. The white solid residue with $\mathrm{mp} .273-275^{\circ} \mathrm{C}, 60 \%$ yield was used without further purification .IR: $1655 \mathrm{~cm}^{-1}, 1444-1635 \mathrm{~cm}^{-1}, 702 \mathrm{~cm}^{-1}$

\subsection{Synthesis of 3-(substituted phenyl) -(1H)-1,2,4-triazole-5-thiol (5)}

Benzoyl chloride or 4-nitrobenzoyl chloride $(0.02 \mathrm{~mol})$ was gradually added to a mixture of 0.02 mol. ,1.8g.) of thiosenicarbazide in $25 \mathrm{ml}$ of dry benzene after complete addition ,the reaction mixture was left at room temperature for 4 hours .sodium carbonate 1 mole was then added the final mixture was refluxed at $100^{\circ} \mathrm{C}$ for 16 hours ,cooled and water was then added ,the p.pt was filtered and dried ,recrystallized from water ,mp. for $5 \mathrm{a} 255-265^{\circ} \mathrm{C}, 63 \%$ yield as white solid, $5 \mathrm{~b}$ $2 \mathrm{mp}=205-207^{\circ} \mathrm{C}$ also as white sold $56 \%$ yield. IR :3205, $1666 \mathrm{~cm}^{-1}, 1460-1625 \mathrm{~cm}^{-1}, 1288 \mathrm{~cm}^{-1}$, $1307 \mathrm{~cm}^{-1}$ and $154 \mathrm{~cm}^{-1}$. 


\subsection{Synthesis of 5-Bromo-6-phenyl-2- [5-substituted phenyl] -(1H)-1,2,4-triazol-2-yl thio methyl pyradazin-3(2H)-one (6)}

Compound $5 \mathrm{a}$ or $5 \mathrm{~b}(0.002 \mathrm{~mol}$.$) in 30$ of acetone was mixed with compound (4), $(0.002 \mathrm{moh})$ and $0.5 \mathrm{~g}$. of potassium carbonate, after complete addition the reaction was refluxed for 2 hours, filtered the filterate was evaporated under reduced pressure the solid residue was then crystallized from petholeum ether/ ethylacetate mixture, mp. of compound a $116-118^{\circ} \mathrm{C}$, yield 55 while for compound b,mp. $=109-11^{\circ} \mathrm{C}$, yield $52 \%$ as yellow crystals. IR: $3361-3070 \mathrm{~cm}^{-1}, 1699-1698 \mathrm{~cm}^{-1}$, $1647-1641 \mathrm{~cm}^{-1}, 1685-1633 \mathrm{~cm}^{-1}, 617-573 \mathrm{~cm}^{-1}$, and $1514,1321 \mathrm{~cm}^{-1}$.

\subsection{Synthesis of 4-Bromo-6-phenyl pyradazin-3-(2H)-one (7)}

Compound (3), $(0.02 \mathrm{ml}, 5.02 \mathrm{~g}$.) and $0.02 \mathrm{~mol} .2 .73 \mathrm{~g}$. of benzoyl chloride in $100 \mathrm{ml}$ of dry benzene ,the reaction mixture was stirred for 12 hour under dry conditions ,the solvent was evaporated under reduced pressure, the residue was dried and recrystallized from ethanol, the brown crystal has $\mathrm{mp}$ of $196-199^{\circ} \mathrm{C}$ and $65 \%$ yield. IR: $1697 \mathrm{~cm}^{-1}, 1658 \mathrm{~cm}^{-1}, 1496-1621 \mathrm{~cm}^{-1}$ and $870 \mathrm{~cm}^{-1}$.

\subsection{Synthesis of 5-Azido-6-phenyl-2-benzoyl pyridazin-3(2H)-one (8)}

A mixture of ( 0.005 mol.,1.8g.) of compound(7) and $0.01 \mathrm{~mol} .0 .65 \mathrm{~g}$. of sodium azide in $10 \mathrm{ml}$ of acetonitrite, the mixture was left at r.t for 24 hour., $25 \mathrm{ml}$ of water was then added after this period .the final mixture was extracted with ether, the ether layer was then washed with $5 \%$ solution of sodium thio sulfate then with water . the solvent was evaporated under reduced pressure resulting in the formation of with solid which was recrystallized from methanol to give white powder $\mathrm{mp}$ $137-139^{\circ} \mathrm{C}$, yield $62 \%$, IR: $2154 \mathrm{~cm}^{-1}, 1655 \mathrm{~cm}^{-1}$ and $1456-161 \mathrm{~cm}^{-1}$.

\subsection{Synthesis of 2-Benzoyl-3-phenyl-5-N (substituted triazoyl) pyridazin-3(2H)-one (9- 11)}

Alkyne or alkene compound $(0.01 \mathrm{~mol})$ was added to a mixture of $(0.005 \mathrm{ml} ., 1.6 \mathrm{~g}$.) of compound(8) dissolved in 30ml. of dry acetone the mixture was refluxed for 12 hour under dry condition cooled ,evaporation of the solvent under reduced pressure affords solid product which was recrystallized from ethanol, the product and yields are as follows; for compound 9,,mp 187$189^{\circ} \mathrm{C}, 60 \%$ yield ,compound $10 \mathrm{mp} .276-278^{\circ} \mathrm{Cyield} 70 \%$ while compound 11 , showed a mp of $211-213{ }^{\circ} \mathrm{C}, 57 \%$ yield as brown and yellow crystals respectively IR :1661-1640 $\mathrm{cm}^{-1}, 1439-1601$ $\mathrm{cm}^{-1}, 1352-1437 \mathrm{~cm}^{-1}$. 


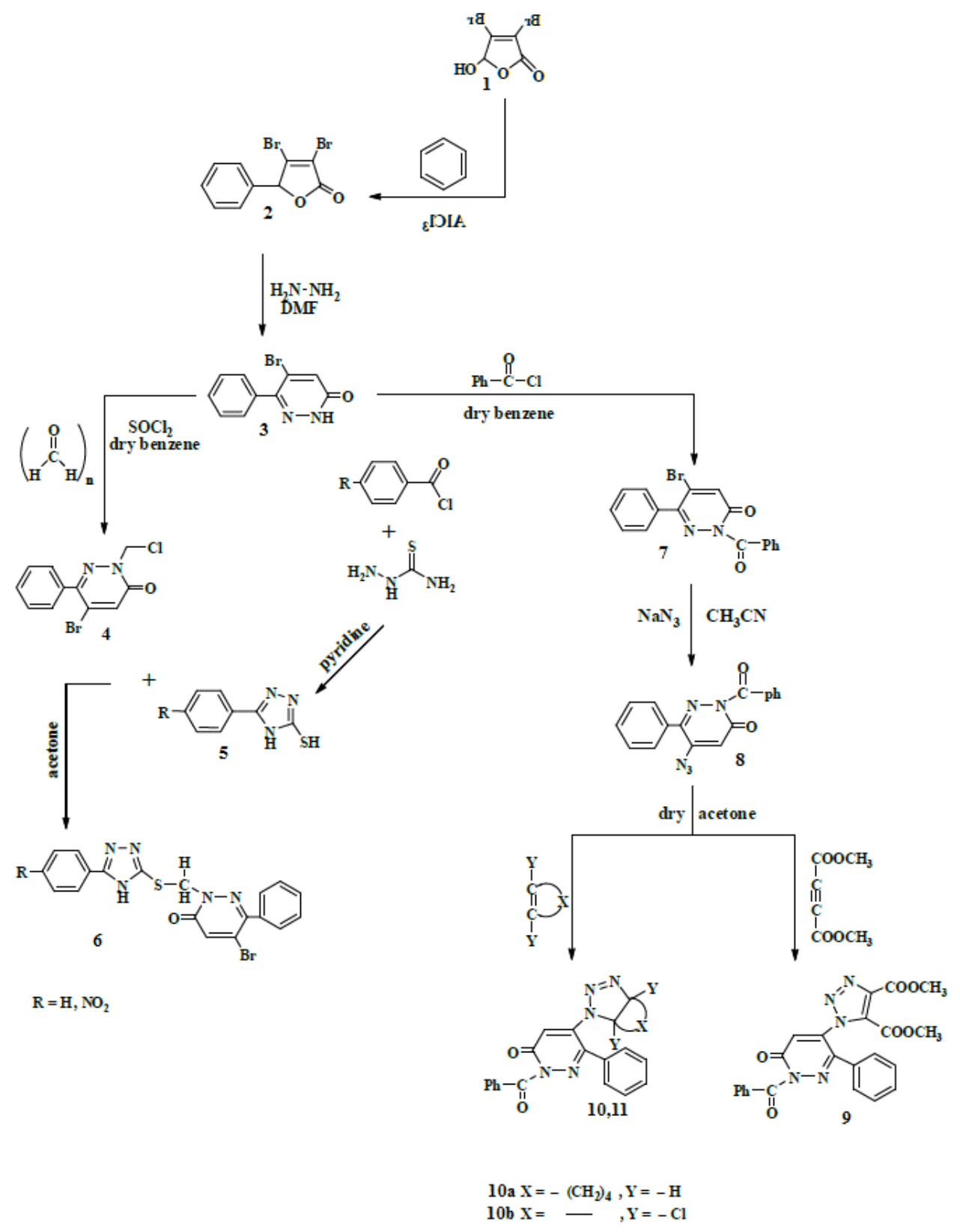

Scheme 1

\section{Results and Discussion}

\subsection{5-Bromo-6-phenyl pyridin-3(2H)-one (3)}

This compound was prepared from treatment of compound (2) with bydrazin in DMF as shown in scheme (1). It is characterized by the following IR absorbation bands $32975 \mathrm{~cm}^{-1}$ for $\mathrm{NH}, 1695 \mathrm{~cm}^{-}$ ${ }^{1}$ for $\mathrm{C}=\mathrm{O}, 1456-1601 \mathrm{~cm}^{-1}$ for $\mathrm{C}=\mathrm{C}$ aromatic, $\mathrm{C}=\mathrm{N}$ while $\mathrm{C}-\mathrm{Br}$ streching vibration observed at 870 $\mathrm{cm}^{-1}$. ${ }^{1} \mathrm{HNMR}$ spectrum showed the following signals $12.4 \mathrm{ppm}$ for NH proton as singlet, 7.41- 
$7.54 \mathrm{ppm}$. for benzene ring $(5 \mathrm{H}), 5.94 \mathrm{ppm}$ for pyridazine ring proton as singlet signal., 3.57 and $2.51 \mathrm{ppm}$ belongs to $\mathrm{OH}$ proton (enolic proton).

\subsection{5-Bromo-2-(chloro methyl)-6-phenyl pyradazine-3-(2H)-one (4)}

The above compound was prepared from the treatment of compound (3) with thionyl chloride and with paraformaldehyde as it was stated in the experimental part. This compound was characterized by $\mathrm{IR} \mathrm{cm}^{-1} 1655,1444-1635,702$ for $\mathrm{C}=\mathrm{O}, \mathrm{C}=\mathrm{C}$ aromatic, $\mathrm{C}-\mathrm{Cl}$ respectively.

\subsection{5-Bromo-2-(chloro methyl)-6-phenylm pyradazine-3(2H)-one (5a, b)}

IR characterization of these compounds were as follows:

$3205 \mathrm{~cm}^{-1}$ for $\mathrm{NH}, 1666 \mathrm{~cm}^{-1}$ for $\mathrm{C}=\mathrm{N}$ while the aromatic protons absorbed between 1460-1625 $\mathrm{cm}^{-1}$ and $\mathrm{C}=\mathrm{S}$ at $1288 \mathrm{~cm}^{-1}, \mathrm{NO}_{2}$ absorbation bands for sym. And a ssym. Appeared at 1307,1514 $\mathrm{cm}^{-1}$ respectively.

\subsection{5-Bromo-6-phenyl-2- $\quad[(5-$ substituted $\quad$ phenyl-(1H)-1,2,4-triazol-2yl thiomethyl pyradazine-3-(2H)-one (Ga,b)]}

IR characterization of this compound showed the following absorption bands:; $3070-3361 \mathrm{~cm}^{-1}$ for $\mathrm{NH}, 1698-1699 \mathrm{~cm}^{-1}$ related to $\mathrm{C}=\mathrm{O}$ while the $\mathrm{C}=\mathrm{N}$ appeared at $1641-1647 \mathrm{~cm}^{-1}$, the aromatic absorption bands appeared between $1485-1633 \mathrm{~cm}^{-1}, \mathrm{C}-\mathrm{S}$ at $573-617 \mathrm{~cm}^{-1}$ and finally the $\mathrm{NO}_{2}$ streching sym and assym . at $1321-1514 \mathrm{~cm}^{-1}$ respectively.

\subsection{5-Bromo-6-phenyl pyradazine-3-(2H)-one (7)}

This compound was prepared from the reaction of compound (3) with benzoyl chloride as shown in scheme (1). It is characterized by the following IR absorption bands : $1697 \mathrm{~cm}^{-1}$ for $\mathrm{C}=\mathrm{O}$ of pyradazine ring , $1658 \mathrm{~cm}^{-1}$ for $\mathrm{C}=\mathrm{O}$ benzoyl amide group and 1496-1621 $\mathrm{cm}^{-1}$ for aromatic and $\mathrm{C}=\mathrm{N}$ which appeared within the same region and finally $\mathrm{C}-\mathrm{Br}$ absorption at $870 \mathrm{~cm}^{-1}$.

\subsection{5-Azido-6-phenyl-2-benzoyl pyradazine-3(2H)-one (8)}

The above compound was prepared from sodium azide and compound (7) as listed in the experimental part of this work.

IR characterization of this compound showed the following absorbation bands $\mathrm{cm}^{-}$ ${ }^{1}, 2154,1697,1655,1456-1601$, for $\mathrm{N}_{3}, \mathrm{C}=\mathrm{O}$ of pyradazine ring, $\mathrm{C}=\mathrm{O}$ of benzamide group while $\mathrm{C}=\mathrm{N}, \mathrm{C}=\mathrm{C}$ for aromatic appeared within the same region.

\subsection{2-Benzoyl-6-phenyl-5-N (substituted triazoyl) pyradazine-3(2H)-one-(9-11)}

The above compounds were prepared from the treatment of compound (8) with Dimethyl cyclohexene, acetylene dicarboxylate (DMAD) and dichloro ethylene as it was stated in the experimental part the reaction involve 1,3-diplor addition between (DMAD) and the azido group resulted into the formation of the corresponding triazoles. compound (9) as shown in scheme (1) 
Compound (9) was afforded by treatment of cap (8) with DMAD while compounds 10 and 11 were obtained by treatment of compound (8) with cyclohexene and dichloro ethylene respectively. All compounds were characterized by the following IR main absorption bands :

$\mathrm{cm}^{-1}: 1640-1661$ for $\mathrm{C}=\mathrm{N}$ and $\mathrm{C}=\mathrm{O}$ of amide group while the aromatic $\mathrm{C}=\mathrm{C}$ absorbed within the same of $\mathrm{C}=\mathrm{N}$ region the ester stretching bands appeared at 1739 and finally the $\mathrm{C}-\mathrm{Cl}$ stretching band absorbed at $721 \mathrm{Cm}^{-1}$.

\section{Conclusion and Recommendations}

We conclude from the above study that triazole, compound(5)when allowed to react with furfural derivative compound (4) resulted into the formation of new type of triazoles $(6 a$ and $6 b)$ while compound(7) which is derived from furfural when allowed to react with sodium azide it forms azidido derivative which intern allowed to react with alkenes or alkyne they cyclized into new triazole derivatives(10a,b and 11) These compounds are new nitrogen based heterocyclic compounds. We knew as stated before that nearly $65 \%$ of anti - cancer drugs granted market approved by FDA between 210-1015 are heterocyclic compounds and about $95 \%$ of heterocyclic compounds are drugs so this type of compounds drew attention of researchers to synthesize this valueable compounds. In our work we have synthesized the above heterocyclic compounds having new nitrogen-based heterocycles which need further studies.

\section{Acknowledgments}

Authors would like to thank the Iraqi Ministry of Higher Education and research for offering Iptisam Mohammad Shabn a scholarship to do this work which is part of her PhD Thesis, Thanks also for the chemistry department of Education college for providing al the facilities to perform this work.

\section{References}

[1] Mohamed S., Mmhamed Y., Amria A., KotabE.R., Antimicrobial Activities of some Synthesized Pyridines, Oxazines and Thiazoles from 3-Aryl-1-(2-naphthyl) prop-2-en-1-ones, Sci Pharm. 2008;76 279-303.

[2] Al-Mulla A., A Review: Biological Importance of Heterocyclic Compound, Der Pharma Chemica;2017, 9(13):141-147

[3] Jyoti M.M., ShastriS., Megharaja H., RashmiK., Farzanabi S. \& Vinay S..Design, synthesis, characterization, and biological evaluation of pyrido[1,2-a]pyrimidinone coumarins as promising anti-inflammatory agents, Synthetic Communications 2018; 48, NO. 4, 375-386.

[4] Bedia K.,KaymakU., Antituberculosis activity of hydrazones derivedfrom 4-fluorobenzoic acid hydrazide, Med Chem Res 2009;18:277-286.

[5] Al-Ajely M.S, Synthesis and Atiplatelet of 2-(ethyl amino acid esters), Amino pyridyl 1,3-oxzine Journal of Advances in Chemistry2013; 2, No. 2.

[6] Najem R.S., Synthesis and biological activity of some new 1,3 -oxazine and 1,3 thiazinederivedfrom (5-amino-1,3,4-thiadiazole-2-thiol),2015;11, No: 2.

[7] Mukhtyar. S.S., Aran K., Jaya D., Rakesh S., Areview: Biological,Significance of Heterocyclic compounds, International Journal of Pharma Sciences and Research2013; 4 No 3 .

[8] Beattie S., Heibron I.M., Iraving F,Dicarbocyanines anew series of cyanine dyes, J. Chem. Soc. $1932 ; 264$. 
[9] Gol'dfarb Y., Tarasova L.D, Bromination products of furfural, Russian Chemical Bulletin1965 14, 1041-1042 .

[10] Stroganova, T, Butin A.., Sorotskaya L.., Kul'nevich V.. Aryl (2- furyl) alkanes and their derivatives, Synthesis of symmetric bis- and tris (2-furyl) methane, Arkat USAInc 2000;641-659 .

[11] Baumann M., Baxendale I.R., Ley S.V., S.V. Nikbin S.V. An overview of the key routes to the bestselling 5- membered ring heterocyclic pharmaceuticals, J.Org. Chem 2011;7,442-495.

[12] Bruno I., De Simone R. "Design, Synthesis and pharma- cological studies of structural analogues modeled on bioactive natural products", $\mathrm{PhD}$. Thesis, University of Salerno (2010)

[13] Yuqin J, Xiaolan C, Lingbo Q, Junliang W, Jinwei Y,Senshen C, and Xu L. An Efficient Ultrasound-assisted Method for the Synthesis of 1,4-Disubstituted Triazoles, Z. Naturforsch. 2011,66b, $77-82$.

[14] Navadiya H.D. Synthesis and application of 3-[4'-(3-hydroxy-4-methyl-phenylazo)-3, 3'dimethyl-biphenyl-4-yl)-2-methyl-3h-quinazolin-4-one and their derivatives Int. J. Chem. Sci. 2009;7(3),, 2056-2062.

[15] Ahmed A.. M, Farid A. B, Azza R. M, Naglaa I. A, ElSendunyF,Alaa A.M., Said M. , Synthesis, antitumor evaluation and molecular modeling study of novel benzimidazoles and pyrazinobenzimidazoles, Journal of Applied Pharmaceutical Science2017; 7 (06),. 206-214.

[16] Elkanzi N.A., Synthesis of pyrimidine and pyrimidinthione, http://heteroletters.org ISSN: 2231 3087(print) on line / 2013; Vol. 3: (1), , 247-268

[17] Yuqin J, Peng Z,Wei L, Xiaojing L, and Guiqing X, An Efficient Synthesis of 1,4-isubstituted Triazoles in Water Z. via CuCl2/Zn-Catalyzed Huisgen Cycloaddition Naturforsch. 2012; 67b, 226 -230 ;

[18] Al-Ajely1M,. Shaban I.M,Synthesis of Some Heterocyclic Compounds Derived from Furfural Journal of Addiction Research 2018; 2 | Issue 1.

[19] a,RichardsonK. GB Pat 2099818 and US Pat 4404216: (1982). b.Zhou CH1, Wang Y. Recent researches in triazole compounds as medicinal drugs, Curr Med Chem.2012;19(2):239-80.

C- Laurent S., Carine B. Filomena De Luca Lionel N., Maud A Paola M. Silvia T.and Luisa B.,1,2,4-Triazole-3-thione Compounds as Inhibitors of Dizinc Metallo-b-lactamases, ChemMedChem 2017;12, 972 - 985.

[20] Blazecka P.G., Curran T., Pflum D. and Zhang J., Further utilization of mucohalic acids: PalladiumFree, Regioselective etherification and amination of $\alpha, \beta$-Dihalo $\gamma$-Methoxy carbonyloxy and $\gamma$ acetoxy butenolides, American Chemical Society 2003;,5(26), 5015-5017.

[21] Song J.Wu.B., Chen H. , Bhadury P. and Hu D., Synthesis and anti-fungal activity of 5- chloro -6phenyl pyridazine -3(2H) -one derivatives, Molecules2009;14,3676-3687.

*Corresponding author.

E-mail address: mohamadalajelee@ yahoo.com 